\title{
POSSIBILITY FOR EFFECTIVE PROTECTION AGAINST BIOLOGICAL WEAPONS
}

\begin{abstract}
Although of micrometric magnitude, the biological weapon used as an act of bioterrorism is a global danger. The possibility of using biological weapons, more and more as a security measure, is considered as a means of subversive activity rather than a means of open warfare. Contemporary bacteriology provides a higher level of techniques for creation of new deadly biological warfare agents. International bans on the production and use of bio agents are not sufficient guarantee and protection against the possible use of such agents in a future total war, nor are any obstacle for use in terrorist goals. Here, the question arises about the possibilities for achievement of total protection expressed through the forms of bio-defence and biosafety. In this paper, there is a systematic attempt made to examine the (un)reasonableness of the horrifying fear of modern genetic engineering technologies and the possibilities for production of new, more dangerous agents. The results of this paper point to relatively reassuring /complacent view in the biomedical community for the premature, but still realistic possibility of an apocalyptic scenario as a consequence of the use of bio agents. In addition to such views, scientific data on the relative efficacy of existing procedures for detection of agents and care of endangered/infected subjects on which antibiotic treatment, antibiotic-based therapies based on passive antibodies and prophylaxis measures will be used are also discussed.
\end{abstract}

Keywords: BIOLOGICAL WEAPONS, BIOPROTECTION, VIRALITY, PROFILACY, IMMUNIZATION

\section{Introduction}

As we sow, so we will reap! There are considerations that biological weapons on a geopolitical scale will determine the fate of our civilization!

According to the Merriam Webster dictionary, biological weapons are harmful biological agents (such as pathogenic organisms or neurotoxins) used as weapons to cause death or illness, usually on a large scale. Also in the category of biological weapons, there are agents that do not harm people directly, but which in some way disturb the economy. In this context, for example, a sufficiently relevant pathogen is the Foot-and-Mouth Disease virus (FMA), which is capable of causing widespread economic damage and pub- 
lic concern (as was the case in 2001 and 2007 with the occurrence of FMD in the United Kingdom), but at the same time, it has almost no ability to infect people. (Daryll, 2002, 42). One of the ways of biological warfare that disturbs a given economy is through an attack over animals, which is intended to eliminate the animal resources used for transport as well as food. Thus, for example, in the 1980s, the Soviet Ministry of Agriculture developed a secret program codenamed Ecology in which forms of diseases Foot and mouth and Rinderpest (against bovine animals), African swine fever (against swine), and Psittacosis (Parrot disease against chickens) have been successfully developed (Alibek and Handelman, 1999).

The question arises about the possible use of biological weapons that would not be in case of open warfare, but as a means of some subversive activity?! In fact, the assessment of biological warfare experts suggests that the more likely way of using biological weapons would be precisely a means of certain sects, terrorist groups and individual crazed acts. Here are a few such relatively recent examples that confirm this: In September and October 1984, about 750 people were deliberately infected by a salmonella agent causing food poisoning, when the followers of the cult Bhagwan Shree Rajneesh contaminated food at restaurants in Oregon; In 1994, the Japanese sect of the AumShinrikyo cult performed an aerosolized release of anthrax from the top of buildings in Tokyo; In 2001, anthrax was delivered through envelope letters to the media and government officials in the United States, an event that resulted in five dead; On 3 February 2004, three US Senate offices were closed after ricin toxin was discovered in the post office of the Senate chief executive, Bill Frist.

Historically, biological warfare has been applied since the ancient period. With the advanced bacteriology since 1900, a higher level of sophisticated techniques for the possible use of bio agents in warfare is created. Almost all major powers in the era of imperialist wars have developed their own programs for the production and use of biological weapons, although those have not been used officially or have achieved significant results where they were used. During the First World War certain cases of deliberate spread of infectious diseases among the warring parties were noticed. ${ }^{1}$ In criminal proceedings in front of international military courts in Nuremberg and Tokyo, it was proved that Germans were infecting prisoners of war with an infectious typhus, while Japanese some camps of prisoners of war with Russians and Chinese have turned into laboratories for the examination of bacterial agents.

\footnotetext{
${ }^{1}$ Thus, the example from 1915 is mentioned when German-American physician Anton Dilger, using a culture of bacterium anthrax and an ulcerative bacterium obtained from Germany, produced about 1 liter of liquid preparation. With this product, with the help of some port workers in Baltimore, he infected about 3,000 horses destined for the coalition forces in Europe.
} 
In the aftermath of World War II, world public opinion expressed great concern about the dreadful consequences of biological weapons. In 1956, Britain closed its biological warfare program, and in 1969 the UK and the Warsaw Pact independently of each other initiated proposals to the United Nations to ban biological weapons that had already previously been banned by the 1925 Geneva Protocol. At the same time, US President Richard Nixon closed the BW production, allowing only scientific research as defensive measures. In 1972, the Convention on Toxins and Biological Weapons was signed by all major powers as a ban on the development, production and storage of microbes or their poisonous products except in quantities necessary for protection and peace research (Henkin, 1993, 408-410).

This Convention is a reaffirmation and amendment to the Geneva Protocol of 1925 . The title 2 of the convention does not contain the ban on the use of biological weapons, since it is considered that this has already been done with the Geneva protocol. The disadvantage of this convention is that it does not provide for international control and verification of its implementation. By 2011, 165 states ratified the convention, including the former USSR, which committed itself to non-producing or non-storing biological weapons. Despite the signing of the convention, the Soviet Union3 continued the research and production of a massive offensive biological weapon in a program called Biopreparat (Alibek and Handelman, 1999). It is estimated that dozens of countries possess offensive biological programs for biological weapons. Iran, Libya, North Korea, Syria, Iraq and Israel were also highlighted as biological club members at the time.

\section{Efficacy of biological weapons}

The question arises as to how reasonable are the horrifies on effects of the use of biological weapons?! An example from 1982, when the anthrax bacterium went uncontrollably out of the military microbiological laboratories in Sverdlovsk, the fourth largest city in Russia, caused 68 people to die from an "unknown epidemic" in the first 48 hours (Vasilevski, 2002, 177). After an armed intervention in the Desert Storm against Iraq in 1991, there was a suspicion of the existence of some mysterious Gulf disease-The Gulf syndrome among returnees-US troops from the Gulf region, causing the Pentagon to take extensive measures to protect from and to prevent the use

\footnotetext{
${ }^{2}$ It is exactly as follows: Convention on the Prohibition of the Development, Production and Storage of Bacteriological (Biological) and Toxic Weapons and Their Destruction.

${ }^{3}$ And nine other suspected countries. See: 26 Countries' WMD Programs; A Global History of WMD Use - US - Iraq War - ProCon.org". Usiraq. procon. org. 2009-05-29. Retrieved 2013-09-05.
} 
of biological weapons. ${ }^{4}$ In the case of the anthrax campaign in the US mentioned in the introduction of the paper, US experts took six weeks to recognize the bioterrorist attack. It was the time that had elapsed since the arrival of the first shipment of sprays from anthrax to the time of establishment of a diagnosis, i.e. identification of the agent. After it was verified that ill persons were those in contact with the envelope letters in which the powder was found, and those who were unlikely to have been infected otherwise, it became clear that it was act of bioterrorism.

Today, a technical possibility has been reached to equip rockets, bombs and grenades with biological substances and to develop a technology for aircraft dispersal of such bio-substances. It is known that each ballistic missile with multiple warheads can carry ten independent dedicated bombs, each of which can be filled with a deadly cocktail of viruses and bacteria that can cause about 50 kinds of deadly diseases. Worrying is the fact that technological information on the production of chemical and biological bombs is easily accessible for the so-called aggressively-minded regimes, as well as for terrorists who in recent years shown more interest in this type of weapon. According to Edward Eisen, head of the US Military Medical Research Institute, in the United States in 1998 it was estimated that the danger and fear of bioterrorism had increased. After the famous terrorist attacks on World Trade Centre and Pentagon with civilian airplanes on September 11, 2001, terrorists declared an anthrax war against the United States by delivering anthrax bacteria through postal items 5 . The experiences from the examples show that the most traumatic consequence of biological weapons is the panic caused and fear among people on all continents, especially in such case of modern mutual communication.

To increased efficiency in the BW operation contributes the method of application of biological weapons as well. If a potential user disseminates biosensing agents in the form of aerosols, the exposure could be much greater (in some locations) than exposure which occurs in natural conditions. Even vaccines that are considered to be effective in protecting against infection that occurred naturally can under such conditions be insufficiently effective, i.e. without satisfying the appropriate degree of protection (Geissler, 1986).

It is quite alarming the possibility of creating new deadly biological agents. This is enabled by new approaches in biotechnology, more precisely synthetic biology. A number of companies have conducted research in terms

\footnotetext{
${ }^{4}$ Special military units were formed to combat possible terrorist actions by chemical or biological means. These units were used to secure the Olympics in Atlanta, also during President Bill Clinton's second inauguration as well as the summit of the seven most developed industrial nations in Denver, 1997.

${ }^{5}$ It was later reported that these terrorist bacteria originated from US military laboratories.
} 
of targeted molecular evolution, a term that implies accelerated evolution directed to the desired direction, so that in some microorganism genetic variations are introduced and then artificial selection is applied. A fairly effective such procedure was developed at the Maxigen company in California, USA. In the process, multiple copies of one gene are separated into fragments and then reconnected with the use of different polymerase chain reaction (PCR). Thus, genes with a different layout of fragments and mutations are obtained, after which such genes are put into microorganisms and then select those with the desired properties. By this way, the time which is necessary to obtain a microorganism with appropriate properties is significantly shortened (from 15 years to 6 months). One frightening case suggests that in this way the species of Escherichia coli was obtained with a gene of resistance that was transferred from staphylococcus, so that the new species became 32,000 times more resistant to the third generation of cephalosporin antibiotic than the wild species. Due to the vigilance of possible abuse this species was immediately destroyed (Dennis, 2001).

Recently, the CRISPR / Cas system has been used as a promising technique for correcting the genes. While other methods take months or years to sequencing the genes, CRISPR reduces this time to weeks (Basulto, 2015).

In addition to enhanced bioweapons efficiency, it is also the fact that the subtle changes in the structure of the proteins of the pathogen agents, as a consequence of the change in its genome, can cause changes in the antigenic composition and thus completely compromise the specific protection that would be achieved by vaccination as a specific prophylactic measure for biosafety. ${ }^{6}$ Although most biological weapons experts believe that the fear of microorganisms created by genetic manipulations is premature and that more should be considered of conventional biological agents, however the government agencies in the United States are already engaged in developing methods for detecting diseases caused by with genetically altered microorganisms.

\section{Efficiency of dealing with the used biological weapons - specific meas- ures of biological protection}

A specific measure of biological protection in healthy individuals is prophylaxis, which may be pre-exposure and post-exposure. It covers the use of vaccines, specific immunoglobulins (immunoprophylaxis) of antimicrobial agents, e.g. antibiotics (chemoprophylaxis) and antitoxins. The use of antibiotics as a post-exposure prophylaxis, as well as in the treatment of patients, should be started as soon as possible, and this therapy must last for

\footnotetext{
${ }^{6}$ Maxigan researchers use this method to improve the production of medicines and proteins, but as with any achievement of science, this could be misused.
} 
long enough. Thus, for post-exposure prophylaxis in the case of exposure to anthrax spores, the recommendation is to last 60 days (as in the treatment of the diseased), that is, to use quinolones or doxycycline in appropriate doses. An explanation for such extended antibiotic prophylaxis is the experimentally confirmed possibility that up to 60 days or even 100 days (CDC, 2001) may occur until the germination of the inhaled anthrax spores. Recent experiences from the United States have shown that individuals who have been reliably found exposed to dust containing anthrax spores have not gotten sick after the antibiotic prophylaxis (Anon, 2001). In case of exposure to other agents of the so-called category A biological agent, such as plague and tularaemia, the recommended prophylaxis is of significantly less duration (seven or fourteen days). There is insufficient documented data on the efficacy of antibiotic prevention of tularaemia and plague. For the treatment of tularaemia, as mentioned above, streptomycin is the best choice. Many experts recommend gentamicin as the first choice for accidents happened in the laboratory (Cross and Penn, 2000).

What makes these drugs unsuitable for massive application in a prophylactic goal is their ototoxicity and nephrotoxicity, as well as the parenteral route of administration. Although the efficacy of ciprofloxacin and doxycycline in humans exposed to aerosols that carry the causers of tularaemia is unknown, mice experiments indicate that these antibiotics given at an early stage, i.e. quickly after exposure, can prevent the development of the disease (Rusell at al., 1998). Anyway, in the treatment of plague sufferers as an alternative to streptomycin also gentamicin, doxycycline, chloramphenicol, quinolones, and even co-trimoxazole have the advantage in post-exposure prophylaxis with respect to mentioned aminoglycosides. In addition, doxycycline has an advantage over ciprofloxacin, chloramphenicol, and co-trimoxazole, but they have also been shown to be effective in preventing the development of the disease (Byrne et al., 1998). The recommended antibiotic prophylaxis in the case of F. tularenis exposure is 14 days, and when it comes to $\mathrm{Y}$. pestis is 7 days. Since it is an asporogenous bacteria, such short-term antibiotic prophylaxis should be sufficient to prevent the disease at the most of exposed ones (Navas, 2002). If it is a pulmonary disease, where there is a possibility for inter-human transmission of the infection through aerosols, in order to prevent further spread of the disease, besides the isolation of the diseased, prolonged antibiotic prophylaxis may be necessary. What should be kept in mind is that it is quite realistic that the aforementioned agents, used as biological weapons, might be resistant to antibiotics that are recommendded for treatment and prophylaxis, in which case these antibiotics would be absolutely useless in the care of the exposed.

As a specific measure, vaccination can also be used, primarily for preexposure prophylaxis, although it can be applied and post-exposure, which depends on the length of the incubation period. Post-exposure immunizati- 
on is a successful prophylactic measure in case of exposure to the variola virus precisely because of the length of the incubation period, which lasts from seven to seventeen days (an average of twelve). This is actually one of the characteristics of the epidemic process of the smallpox, which was of great importance in it eradication, because it was possible to vaccinate the exposed faces in the hotspot itself. Immunization only with smallpox vaccine is recommended in cases where exposure has lasted less than three days. In the same period, passive immunization of the exposed by intramuscular application of vaccinia immuno globulin (VIG) in doses of $0.6 \mathrm{ml} / \mathrm{kg}$ is possible. If from the time of exposure to the agent has passed more time, then specific immunoglobulins are required besides the vaccine. Vaccination is contraindicated in pregnant women, immunosuppressed individuals, HIV-infected and eczema-infected patients, although in all of them should be measured the risk that vaccination brings with the possibility of smallpox disease after exposure to the virus. If, however, it is decided to vaccinate, then it is mandatory that VIG to be given together with the vaccine (Judith et al., 1999, 25).

\section{Basic procedure for bio protection in case of suspected bioterrorist at- tack}

In the attempts for bioterrorist actions through suspicious shipments (as an unknown sender, incomplete or wrong address, blurred or deformed shipment, the presence of solid objects in it, unusual smell, etc.), the shipment should not be opened, neither shaken, nor squeeze, but should be put in a plastic bag, or in a solid packaging with a lid or cover it (with paper, plastic foil and some clothes). Thereafter, the room should be abandoned, other people who are present in the room should be informed in order to leave the room, and then the premises should be locked or otherwise ensured that nobody will enter. The activities that follow are: hand washing with water and soap and reporting to the competent state (health and safety) services. If the shipment is damaged or open and suspicious content is detected, it should not be moved, but immediately covered by any improvised means and as in the previous case to leave the room and prevent entry into it until the arrival of the representatives of the competent services. Should it happen that dust is poured through parts of the body or clothing, it should not be removed with hands or clothes shake. Then it becomes possible, carefully, without raising dust, to take off clothes and to put it off in appropriate packaging and to bathe the body. In cases where in air-conditioned buildings appearance of dust or tiny droplets in the air is shown or there is a suspicion that a biological weapon has been used by aerosols, the ventilation system should be switched off as soon as possible, and the premises is to be quickly left, closing behind the doors from the room. In such cases of bioterrorism actions, it is obligatory to make a list of the exposed persons. 


\section{Conclusion}

Although of micrometre size, biological agents pose a threat to the global level. Biological weapons consist of microorganisms, viruses and bacteria that, when enter the victim's body, they multiply very quickly and destroy it from within. Their production is cheap and fairly simple, despite their monstrously powerful action of unlimited multicipation and attacking new people ... in thousands. The amount needed to use such microorganisms as biological weapons is very small. This weapon, unlike conventional weapons, has no single use, but its initial use is only the beginning of one devastating military deadly campaign.

Anthrax is most easily produced and easily spread, causing deadly pneumonia (one hundredth of a millionth of a gram is enough to kill a person). In addition to the anthrax, biological combat assets are specifically referred to as ricin, is that attack the kidneys and create genetic problems; entrovirus, causing blindness; botulinum, the deadliest poison on the planet transmitted by consumption of infected animals and products of animal origin, as well as aflatoxin, containing carcinogens. Earlier known biological bombs include smallpox, a highly contagious virus, one of the greatest killers in history, as well as a plague, a deadly contagious disease (more infectious than anthrax), which is transmitted from person to person or by insect bite.

Bioterrorism is a reality of the modern world and therefore appropriate preparations are necessary in order to be able to implement the appropriate protection measures. The goal of such preparations is to reduce the consequences of a possible biological attack, primarily with rational and timely response. It is necessary to establish an appropriate monitoring system, to equip microbiological laboratories for the rapid detection of biological agents with the appropriate level of biological protection, that is, with appropriate stationary healthcare facilities for care and treatment of the sick. In order for all this to function properly, a clear division of work and experts with appropriate profiles are required, which would be constantly improved. It is also necessary to provide sufficient stock of drugs, vaccines and other indispensable sanitary material. All of this involves a significant engagement of material and professional potentials, which is not an easy task for any country.

There is hope in prospect for the development of therapies based on antibodies that rely on technology that can react quickly to new threats, as opposed to the creation of new biological agents that will almost certainly require significant specialist research and development. 


\section{References}

26 Countries' WMD Programs; A Global History of WMD Use - US - Iraq War-ProCon.org". Usiraq.procon.org. 2009-05-29. Retrieved 2013-0905 .

Alibek, K. and K Handelman. (1999). Biohazard: The Chilling True Story of the Largest Covert Biological Weapons Program in the World Trade From the Inside by the Man Who Ran It. New York: Random House.

Anon. (2001). Investigation of bioterrorism-related anthrax, 2001. MMWR Morb Mortal Wkly Rep. vol. 50, 1008-1010.

Basulto, D. (2015). "Everything you need to know about why CRISPR is such a hot technology." The Washington Post. November 11. Accessed February 28, 2016.

Byrne, W. R., Welkos S. L., Pitt M. L. et al., (1998). Antibiotic treatment of experimental pneumonic plaque in mice. Antimicrob Agents Chemother, Vol. 42, 675-681.

CDC. (2001). Regarding Additional Options for Preventive Treatment for Those Exposed to Inhalational Anthrax. HHS News. $18 \mathrm{dec}$.

Cross, J. T., Penn R. L. (2000). "Francisellatularensis (tularemia)". In Principles and practice of infectious diseases, edited by Mandell G., Philadelphia, Pa: Churchill Livingstone, 2393-2402.

Daryll, E. R. (2002). „Bioterrorism-the high economic cost of an attack“, In MidAmerica Farmer Grower. Vol. 19, 42.

Dennis, C. (2001). „The bugs of the war". In Nature, 411, 232-235.

Geissler, E. 1986. Biological and toxin weapons today. SIPRI, Oxford University Press, 55-76.

https://www.washingtonpost.com/news/innovations/wp/2015/11/04/everyth ing-you-need-to-know-about-why-crispr-is-such-a-hot-technology/?u tm_term $=$. a50ceca43b05

Judith, F., et al., (1999). Document: Bioterrorism Readiness Plan: A template for Healthcare facilities. Department of the Navy USA.

Navas, E. (2002). "Problems associated with potential massive use of antimicrobial agents as prophylaxis or therapy of a bioterrorist attack." In Clinical Microbiology and Infection. Vol. 8, 534-539.

Василевски, В. (2002). Меѓународно хуманитарно право. Скопје: Воена академија „Генерал Михаило Апостолски“. 